\title{
A STANDARD MICROCONTROLLER BASED DISCRETE-TIME PI FOR CONTROLLING THE MOTION OF A DC-GEARMOTOR.
}

\author{
C. Hernández-Rosales', R. Femat', E. Ruiz-Velázquez², G. Solís-Perales³. \\ ${ }^{1}$ División de Matemáticas Aplicadas y Sistemas Computacionales, IPICYT, \\ Apdo. Postal 3-74, 78231, San Luis Potosí, S.L.P., México. heros@ipicyt.edu.mx - rfemat@ipicyt.edu.mx \\ ${ }_{2}$ Facultad de Ingeniería, Universidad Autónoma del Carmen, Campeche, México. \\ ${ }^{3}$ Facultad de Ingeniería, Universidad Autónoma de Yucatán, Yucatán, México. \\ Received: November $14^{\text {th }}$, 2003. Accepted: February $17^{\text {th }}, 2005$
}

\section{ABSTRACT}

This paper shows how the INTEL ${ }^{\circ}$ D8751 H microcontroller can be used to control the motion of a DC-Gearmotor. One advantage of this design is that does not require external memory RAM/EPROM to perform the control of the motor. A precision potentiometer and an analog-to-digital converter (ADC) are used to measure the motor angular position. The ADC is driven by the ALE signal from the microcontroller; therefore an external signal clock is not required. In order to implement a discrete-time PI controller and a discrete-time filter, specific libraries were designed. Moreover, other libraries based on micro $C^{\circledR}$ compiler, has been modified. Finally, experimental results show a good performance of the embedded system.

\section{RESUMEN}

Este articulo muestra como el microcontrolador $\mathrm{D} 8751 \mathrm{H}$ de INTEL $^{\circ}$, puede ser utilizado para controlar el movimiento de un Moto-reductor de corriente directa. Una ventaja de este diseño es que no necesita memoria externa RAM/EPROM para controlar el motor. Para medir la posición angular del motor un potenciómetro de precisión y un convertidor analógico a digital son usados. Este ADC utiliza la señal ALE generada por el microcontrolador como señal de reloj y por lo tanto una señal externa de reloj no es necesaria. Además para poder implementar el controlador PI y el filtro digital se tuvieron que desarrollar rutinas especiales y modificar otras basadas en el compilador $C^{\circledR}$. Finalmente los resultados experimentales muestran un buen desempeño del sistema completo.

KEYWORDS: Embedded Systems, Microcontrollers, Discrete-Time PI controllers, Digital Filters

\section{INTRODUCTION}

In recent times, eight-bit microcontrollers became the backbone for the solution of applications of intermediate complexity, and have overcome the microprocessors, especially, in areas where high integration and save of space are required. From a technical standpoint, the main difference among them is that, in the first ones, input/output (I/O) ports and internal memory RAM/ROM are included. Thanks to these features, the microcontrollers are used in applications of process control; for instance, in the automotive [1], industrial and appliance areas, among others [2]. Notice that adding ROM and RAM memory to a microprocessor will not create a microcontroller, but on the other hand, a microcontroller can be used like a microprocessor when the system requires external memory. The drawback of adding external memory to a microcontroller is that the $\mathrm{I} / \mathrm{O}$ ports accessible for the user are less. In some cases the 
designer extends the remaining $\mathrm{I} / \mathrm{O}$ ports by adding hardware to the design [3]. For this reason, nowadays many manufacturers produce new microcontrollers with extending internal memory RAM/ROM. Examples of these microcontrollers are the enhanced version of INTEL ${ }^{\circledR}$ MCS-51, series 87C51RA/RB/RC whose mean features are respectively 8/16/32 KB of internal memory EPROM. Moreover, there are microcontrollers for specific applications of INTEL $^{\odot}$ series $87 \mathrm{C} 51 \mathrm{FA} / \mathrm{FB} / \mathrm{FC}$ (see table I), that incorporate the programmable counter array (PCA), allowing the following attributes: a) high speed I/O ports, b) compare/capture registers, C) pulse width modulator (PWM) and d) watchdog timer. Because these characteristics the 87C51FX microcontrollers allow an easy control of DC motors with minimal hardware [4]. Other example of enhanced version of microcontrollers is the series DS5000T by Dallas Semiconductors $^{\circledR}$, their advantages are the $32 \mathrm{~KB}$ of internal memory RAM and the real-time clock. As a result, $32 \mathrm{~KB}$ of variables and/or data can be stored and updated during the execution of the main program, which makes it ideal for data logging applications [5].

Although the performance of microcontrollers is steadily improved, its cost increases too. For commercial reasons, we present an application using a standard D8751H microcontroller in combination with cheap devices to regulate the angular position of a small Gearmotor. This microcontroller is limited in comparison with the 87C51FB (see table I). However we shall demonstrate that a discrete-time control can be implemented into this simple microcontroller. Moreover, this can be achieved without using neither external memory RAM/EPROM (although 16 and 32-bits operations are used) not external clock signal to drive the ADC.

Table I. Main features of the 87C51FB and D8751H microcontrollers.

\begin{tabular}{|c|c|c|c|c|c|c|c|c|}
\hline MODEL & $\begin{array}{c}\text { EPROM } \\
\text { BYTES }\end{array}$ & $\begin{array}{c}\text { RAM } \\
\text { BYTES }\end{array}$ & $\begin{array}{c}\text { 16-BIT } \\
\text { TIMER }\end{array}$ & $\begin{array}{c}\text { TECH- } \\
\text { NOLOGY }\end{array}$ & $\begin{array}{c}\text { 8-BITS } \\
\text { PORTS }\end{array}$ & INT's & $\begin{array}{c}\text { SERIAL } \\
\text { PORTS }\end{array}$ & $\begin{array}{c}\text { SPEED } \\
\text { CLOCK }\end{array}$ \\
\hline $8751 \mathrm{FB}$ & $16 \mathrm{~KB}$ & 256 & 3 & CHMOS & 4 & 7 & 1 full-duplex & 20MHZ \\
programable & & & & & & & & \\
\hline D8751H & $4 \mathrm{~K}$ & 128 & 2 & HMOS & 4 & 5 & full-duplex & $12 \mathrm{MHZ}$ \\
\hline
\end{tabular}

The controller implemented into the D8751H, is a classical discrete-time PI controller. The motor angular position is measured by using a precision potentiometer which was attached to the motor shaft by means of a gear train. However, because the potentiometer is a mechanical device, this sensor generates electrical noise in the measured signal. A digital filter has been implemented to diminish the effects of noisy measurements in the feedback loop. For the implementation of the filter and the Pl-controller into the $\mathrm{D} 8751 \mathrm{H}$, special arithmetic routines were designed. Thus, in spite of the fact that this microcontroller has a limited 8- bit arithmetic logic unit (ALU), it cannot a priori perform operations such as subtraction and multiplication with 32 bits, but with the designed routines these operations are allowed (these routines are also a contribution of this work).

The paper is organized as follows: Section 2 contains a brief description of the control problem. In Section 3, the instrumentation of the feedback control for the Gearmotor is displayed. In Section 4, experimental results are presented showing the performance of the system and finally, Section 5 contains some conclusions.

\section{DESCRIPTION OF THE CONTROL PROBLEM}

In this section we describe the control scheme and the stages that conforms our design. The block diagram of the sample-data system is depicted in Figure 1. Here, $r(k T)$ denotes the reference signal, $\mathrm{u}(t)$ is the control voltage, $y(t)$ stands for the output signal, $\hat{y}(k T)$ represents the filtered sensor output, $\hat{e}(k T)$ is the error defined by $r(k T)-\hat{y}(k T), d(t)$ designates a disturbance input to the plant, and $n(t)$ describes the noise in the sensor [6]. 


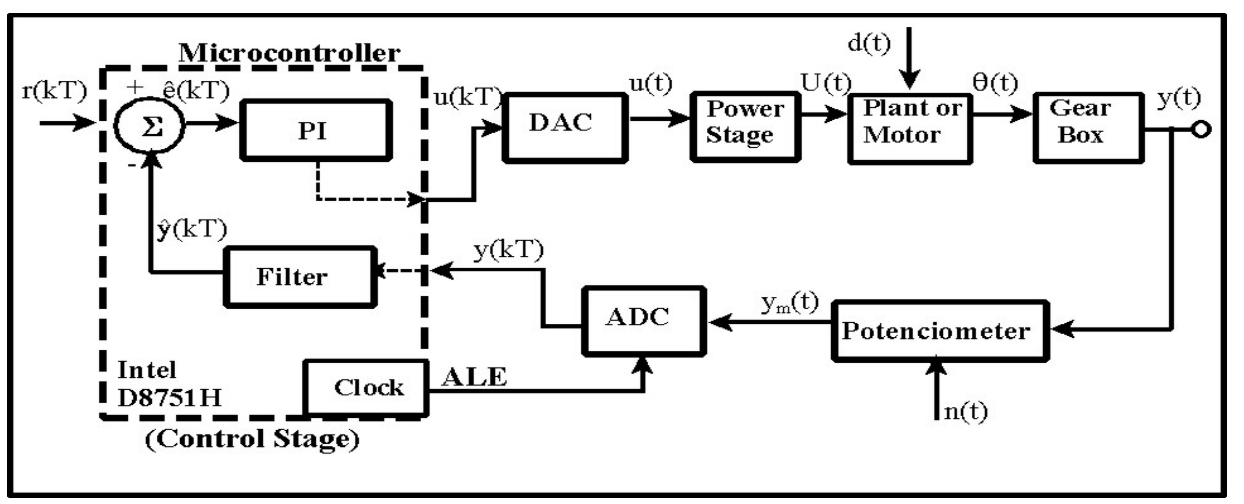

Figure 1. Block diagram of the control scheme

The proposed control scheme is a classical PI feedback procedure. The analog signal measured by the potentiometer, $y_{m}(t)$, is converted to a digital signal by means of the ADC device. The microcontroller calculates the error $\hat{e}(k T)$ and performs the PI-controller action in order to provide the output $u(k T)$ as a discrete signal. Such an output is then converted to the analog form, $u(t)$, by the DAC [7]. In the following subsections, the features of the corresponding stages (see Figure 1) are briefly described.

\subsection{Control stage (microcontroller)}

This block contains the control unit, and comprises: (i) the control algorithm, (ii) the discrete-time filter, and (iii) the libraries designed to perform arithmetic operations. We have called them the "8751 Calculator". It consists of the followings routines:

a) The sum routine for the addition between two 32-bit numbers.

b) The routines for: (i) subtractions of two 16-bit numbers and (ii) subtractions of two 32-bit numbers.

c) A routine to perform the multiplication between two 16-bit numbers.

d) Another one to perform the multiplication of a 16-bit number with a 24-bit number.

e) The division routines performing: (i) the quotient between two 16-bits numbers and (ii) the quotient of two 32-bits numbers.

\subsection{Digital-to-analog stage (DAC)}

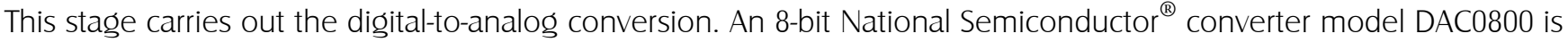
used. The noise immune inputs of the converter accept TL levels with the logic threshold pin (VLC) grounded, changing the VLC potential to allow direct interface to other logic families. One advantage of this converter is that its performance and characteristics are unchanged over the full power supply range ( \pm 4.5 to \pm 18 Volts). Such a converter is used in basic-bipolar output operation with $\mathrm{a} \pm 10$ Volts range and a reference voltage $\left(\mathrm{V}_{\mathrm{REF}}\right)$ of +10 Volts. The resolution voltage is given by $\mathrm{u}(t)=\mathrm{V}_{\mathrm{REF}}[(-255 / 256)+(2(\mathrm{u}(k T)) / 256)]$, where $\mathrm{u}(k T)$ is the input code (calculated by the control algorithm) and $\mathrm{u}(t)$ is the analog voltage supplied to the motor [8].

\subsection{Power stage}

The power stage was implemented with power PNP and NPN Darlington transistors, model TIP-125 and TIP-122 respectively using a "BOOSTER" current amplifier configuration with an operation ranging from 0 to \pm 10 VDC. This stage amplifies the output current of the DAC from $10 \mathrm{~mA}$ to 8 Amperes to provide the necessary current to the motor. 


\subsection{Plant (gearmotor)}

The plant is a 7.5 Watt DC Gearmotor of the company Globe/Motors; CMM series, Model 317A248-1, 24 Volts, torque at normal load $2.12 \mathrm{~N} \cdot \mathrm{m}$, the maximum current at no load $0.37 \mathrm{~A}$, the maximum current at normal load 0.60 amperes, gear reduction radio 2304:1, RPM at 24 VDC without load $7.5 \pm 0.6 \mathrm{rpm}$, RPM with rated load $5.5 \pm 0.5 \mathrm{rpm}$, the length of the motor with gearbox is of $9.677 \mathrm{~cm}$. The Gearmotor is controlled by armature and its field is a permanent magnet, the input to the plant is a DC voltage and the measured plant output is the angular displacement, $\theta(t)$.

\subsection{Measurement stage (precision potentiometer)}

The sensor is a precision potentiometer, model S-7286, with a $5 \mathrm{~K} \Omega$ resistance and 10 maximum turns. It is supplied with +5 Volts, and gives 500 millivolts per turn, so that the voltage provided by the potentiometer is $1.38 \mathrm{mV}$ per degree. Therefore, the angular position of the motor is given in volts through the following relationship: $1.38 \mathrm{mV}=1^{\circ}$ $=0.017$ radians.

\subsection{Analog digital stage (ADC)}

In this stage, a National Semiconductor ${ }^{\circledR}$ ADC1241CIJ, CMOS 12-bit plus sign analog-to-digital converter is used. The ADC1241 is a successive-approximation converter, and consists of a digital-to-analog converter (DAC) and a successiveapproximation register (SAR). Such a converter has the capability to perform Auto-zero or Auto-cal routines to minimize the zero error (which is caused by offset voltage of the comparator) and the full-scale and linearity errors (of the DAC). The analog input is tracked and holds by the internal circuitry of the converter, and therefore, does not require an external sampler and holder. An analog signal from 0 to +5 Volts or from 0 to -5 Volts can be converted; for positive inputs, the converted signal is a digital word of 12-bits, but in the case of negative inputs a 13-bit digital word is given in 2-complement representation. In both cases the result can be read in a direct form. The minimal converted voltage is $\mathrm{a} \pm 1.22 \mathrm{mV}$ signal using a reference voltage of +5 Volts. This ADC is driven by the internal ALE signal of the microcontroller with an operation frequency of $1.8432 \mathrm{MHz}$ [9].

All these blocks comprise the sample-data system with the main goal of achieving the control of the angular position of the motor by using cheap and commercial devices that help to minimize the cost of the whole system, preserving at the same time an acceptable performance. In this manner, the design is proposed as an alternative in applications of servomechanisms.

\section{INSTRUMENTATION.}

In this section, the instrumentation of the control system is detailed. That is, we discuss (i) the electronic card including the stages of analog-digital and digital-analog conversions, and (ii) the microcontroller-based electronic card containing the discrete-time filter and the discrete-time PI controller. The selection of parameters of the controller is based on root locus design in continuous-time. The implementation of PI-controller is obtained following the typical ztransfer function representation [6]. 
a)
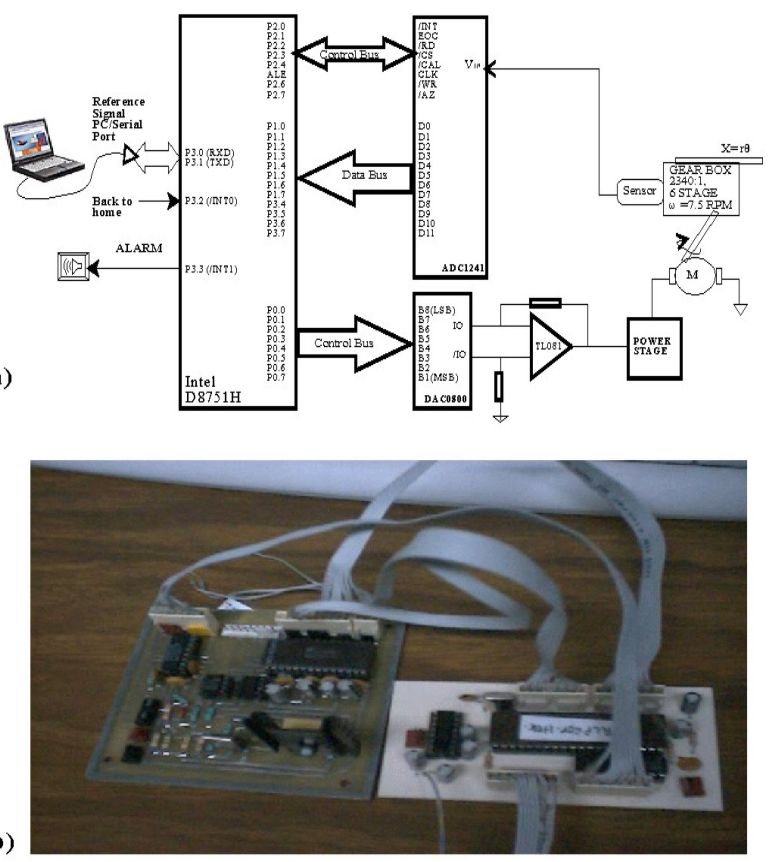

Figure 2

Figure 2. Instrumentation of the control system: a) Schematic diagram for the control of a DC Gearmotor. b) Picture of the electronic boards for the DC Gearmotor

3.1 Implementation of the digital filter

Figure 3(a) shows the open-loop response of the plant for step changes from 0 to +5.2 Volts. The signal is the measured voltage by the potentiometer before its conversion to angular displacement. Since we consider that the potentiometer has no dynamics, this signal is proportional to $\theta(t)$. However notice that in Figure $3(a)$ the signal is contaminated by noise that can be attributed to internal friction in the potentiometer or external factors.

In order to attenuate the electrical noise in the feedback signal, a Butterworth-type filter was implemented into the microcontroller. The designed filter is a second order transfer function, obtained by using the "butter" command of the "Signal Processing Toolbox" of Matlab ${ }^{\odot}$. The order of this filter was chosen by comparing its performance with other filters of high order, and taking into account that the resulting filter should be implemented in the microcontroller.

The continuous transfer function of the filter is given by

$$
\frac{\hat{y}(s)}{y_{m}(s)}=\frac{400}{s^{2}+40 s+400}
$$

where $\hat{y}(s)$ is the filtered feedback signal (i.e. the filter output) and $y_{m}(s)$ is the measured signal. Here, a cut frequency of $6 \pi$ radians and a damping ratio $\zeta_{f}=1$ were selected for the design of the filter. Applying the Laplace inverse transform in equation (1), we get the continuous-time representation of the filter. Then, by using finite differences with a sampling-time of 10 milliseconds, which is sufficient for this application because the angular speed of the 
motor is reduced by a gear box, the discrete representation of the filter is given by

$$
\hat{y}_{k}=\left[A_{1} \hat{y}_{k-1}-A_{2} \hat{y}_{k-2}+A_{3} y_{m k}\right]\left[\frac{1}{A_{4}}\right]
$$

where $A_{1}=3 \mathrm{CH}, \mathrm{A}_{2}=19 \mathrm{H}, \mathrm{A}_{3}=01 \mathrm{H}$, and $\mathrm{A}_{4}=24 \mathrm{H}$, in the hexadecimal base. Figure $3(\mathrm{~b})$ show the open-loop response to the input step of +5.2 Volts, once that equation (2) has been implemented in the microcontroller. Note that the noise is almost removed which means, that the performance of the filter is acceptable. Thus, once the noise was filtered, we proceed to implement the discrete-time PI controller.

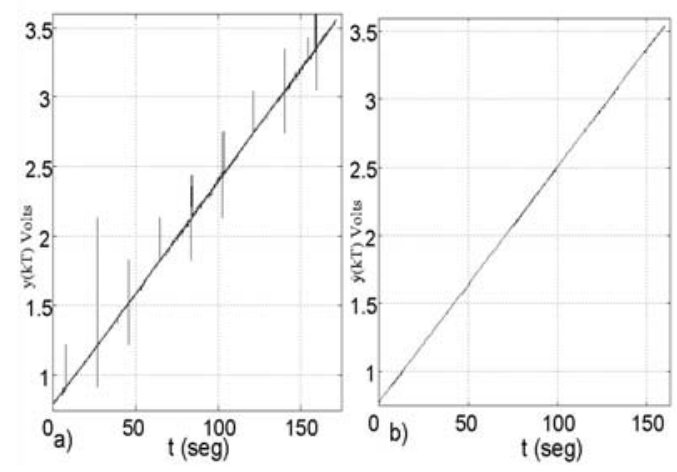

Figure 3. Opened-loop system response: a) For a step change from 0 to 5.2 Volts. b) For the same step change, but using the second order filter in equation (2)

\subsection{PPI- Controller synthesis}

The closed-loop system is built by means of the root locus method design in continuous-time [7, 10]. In this case, the parameters in the controller were chosen such that the closed-loop system is stable and satisfying, at the same time, some performance requirements. Figure 4 shows the closed-loop configuration of the system. For the design, all transfer functions, i.e., the motor plant, Pl-controller and the digital filter, should be in Laplace form to prove the absolute stability in continuous-time, and, thereafter to prove the stability of the system in discrete-time.

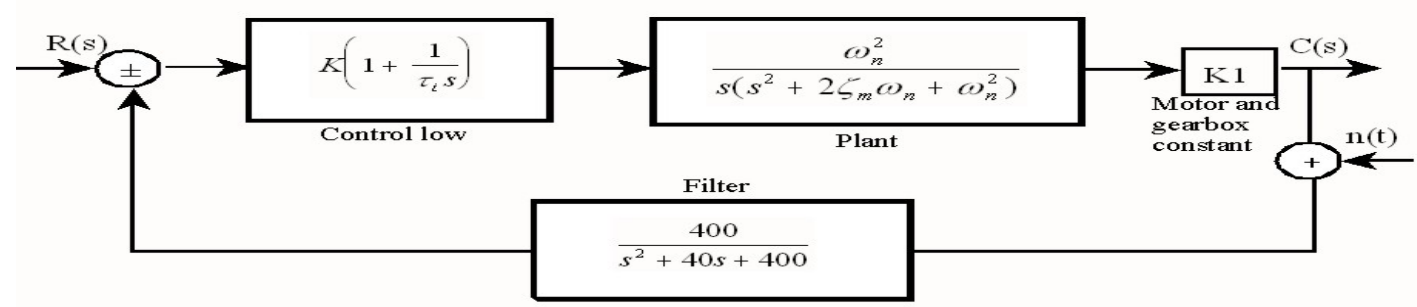

Figure 4. Closed-loop system configuration

The angular position of a DC motor can be represented by a third order transfer function [10], see also reference [11], page 54 , chapter 2 .

$$
\frac{\theta(s)}{U(s)}=\frac{K_{T}}{s\left((J s+B)(L s+R)+K_{T} K_{E}\right)}
$$


where $\theta(s)$ is the angular position (RPMs), $U(s)$ is the control input (Volts), $K_{T}$ is the torque constant (oz.in./Amp), $K_{E}$ is Back EMF or electrical constant (Volts/1000RPM), $J$ is the rotor inertia (oz.-in.-Sec ${ }^{2}$ ), $B$ is the viscous friction coefficient of the rotor (oz.in./sec), $R$ is the electrical resistance $(\Omega)$, and $L$ is the electrical inductance $(\mathrm{mH})$ ). For this Gearmotor the follow parameters are known, and the units are in the English system [12]: $K_{\varepsilon}=1.289 \mathrm{e}^{-3} \mathrm{Volts} / \mathrm{RPM}$, obtained of the equation $K_{E}=\left(K_{T} / 1.35\right), K_{T}=1.74$ oz.-in./Amp, $\mathrm{L}=2.564 \mathrm{mH}, \mathrm{R}=67.9$ ohms, $\mathrm{J}=5.2 \mathrm{e}^{-5}$ oz.-in.-sec . On the other hand, due to the high value of the Gearmotor torque (1250 oz-in.), in this application the friction present in the gearbox and the viscous friction coefficient is assumed negligible and therefore, from (3), we obtain the following plant for the motor, $G_{m}$ :

$$
G_{m}=\frac{\theta(s)}{U(s)}=\frac{\frac{K_{T}}{J L}}{s\left(s^{2}+\frac{R}{L} s+\frac{K_{T} K_{E}}{J L}\right)}=\frac{K_{1} \omega_{n}^{2}}{s\left(s^{2}+2 \zeta_{m} \omega_{n} s+\omega_{n}^{2}\right)}
$$

where $\zeta_{\mathrm{m}}$ and $\omega_{\mathrm{n}}$ are the damping ratio and the natural frequency of the motor respectively and $K_{1}=(90 / 3204)$ is the motor and gearbox constant. Thus by substituting the parameters in (4), the transfer function of the motor can be obtained. On the other hand, by using the transfer function of the Pl-controller.

$$
G_{c}(s)=\frac{u(s)}{e(s)}=K_{c}\left[1+\frac{1}{\tau_{i} s}\right]
$$

where $K_{c}$ is the proportional gain and $\tau_{i}$ is the reset time [7], the characteristic polynomial of the closed-loop system (see Figure 4) is given by

$$
s^{6}+\left(\beta_{1}\right) s^{5}+\left(\beta_{2}\right) s^{4}+\left(\beta_{3}\right) s^{3}+\left(\beta_{4}\right) s^{2}+\left(\beta_{5}\right) s+\left(\beta_{6}\right)=0
$$

where, $\beta_{1}=\left[2 \zeta_{m} \omega_{n}+40\right], \beta_{2}=\left[\left(\omega_{n}\right)^{2}+80 \zeta_{m} \omega_{n}+400\right], \beta_{3}=\left[40\left(\omega_{n}\right)^{2}+800 \zeta_{m} \omega_{n}\right], \beta_{4}=400\left(\omega_{n}\right)^{2}, \beta_{5}=400 K_{c} K_{1}\left(\omega_{n}\right)^{2}$, $\beta_{6}=\left[400 K_{c} K_{1}\left(\omega_{n}\right)^{2}\right] /\left(\tau_{i}\right)$. Thus the root locus of the system is shown in Figure 5 . Since $\omega_{\mathrm{n}}, \zeta_{\mathrm{m}}, K_{1}$ and $\tau_{\mathrm{i}}$ are positive numbers, by Hurwitz criterion, $K_{c}>0$ is sufficient to guarantee stability. Then, the controller parameters can be chosen such that the closed-loop contains a pair of dominant complex poles. In this case, we place the poles such that the damping ratio is 0.9 and the settling time is 6 seconds. Thus, the parameters of the PI-controller are $K_{c}=250$ and $\tau_{\mathrm{i}}=0.89$. We can observe from Figure 5 that with these control parameters the closed-loop system is stable. The poles in closed-loop with these parameters are: $\mathrm{P}_{1}=[-21.1898], \mathrm{P}_{2}=[-18.4851], \mathrm{P}_{3}=[-6.0692], \mathrm{P}_{4}=[-1.6261+$ $0.9572 \mathrm{j}], \mathrm{P}_{5}=[-1.6261-0.9572 \mathrm{j}], \mathrm{P}_{6}=[-0.0036]$ and the zero is $\mathrm{Z}_{1}=[-0.0036]$.

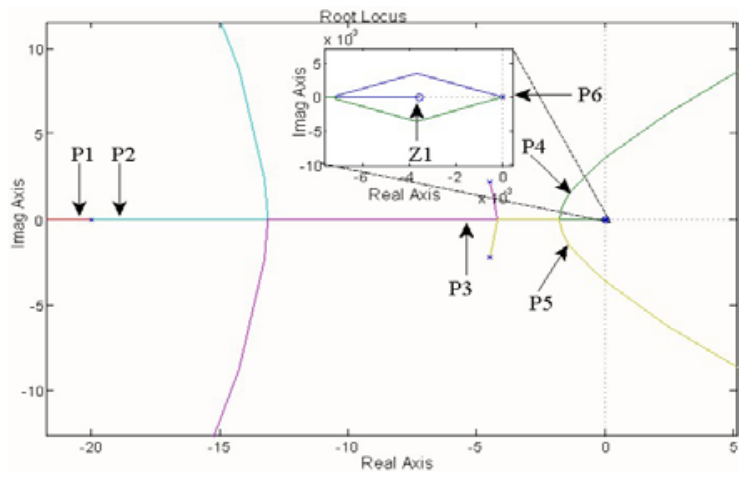

Figure 5. Root locus of the closed-loop system of Figure 4, where PIS, $i=1,2, \ldots 6$, denote the locations of the poles for $K_{c}=250$ 


\subsection{Digital implementation of closed-loop system}

Once the controller in continuous-time was designed, the stability of the closed-loop system in discrete-time should be proved. The discrete-time representation (see Figure 4) was obtained by using the Tustin approach [6]. The transfer function of the closed-loop system equivalent to the discrete-time representation becomes

$$
\frac{C(z)}{R(z)}=\frac{2.11 E^{-8} z^{6}+8.46 E^{-8} z^{5}+1.067 E^{-7} z^{4}+2.358 E^{-9} z^{3}-1.032 E^{-7} z^{2}-8.326 E^{-8} z-2.087 E^{-8}}{z^{6}-5.547 z^{5}+12.807 z^{4}-15.745 z^{3}+10.873 z^{2}-3.998 z+6118 E^{-4}}
$$

The poles and zeros of this transfer function are in the unit circle, which guarantees the closed-loop stability. At this point, we proceed with the implementation of the discrete-time Pl-controller and digital filter. Thus we use the typical representation in discrete-time for the Pl-controller, which is given by:

$$
U(z)=\left[K_{p}+\frac{K_{i}}{\left(1-z^{-1}\right)}\right] e(z) .
$$

For the digital implementation of (8) we also use the finite difference approach, substituting $z$ by $k$, and $z^{-1}$ by $k-1$. In this way we have: $U_{k}=U_{k-1}+K_{p} e_{k}-K_{p} e_{k-1}+K_{i} e_{k}$, where $K_{p}=K_{c}-\left(K_{i} / 2\right)$ and $K_{i}=K_{c} T / \tau_{i}$, which gives $K_{p}=248.6$ and $K_{i}=2.8$ with a sample-time of $\mathrm{T}=10$ milliseconds. We obtain:

$$
U_{k}=\left(U_{k-1}\right)+\left[\left(K_{I N T}\right) e_{k}-\left(K_{P R O P}\right) e_{k-1}\right]\left[\frac{1}{\operatorname{CoefPI}}\right],
$$

where $K_{P R O P}=K_{p}=9 B 6 H, K_{I N T}=K_{p}+K_{i}=9 D 2 H$, and CoefPI $=64 H$, in the hexadecimal base. Using Eq. (9) and Eq. (2), the controller and filter could be implemented in the microcontroller. To obtain $U_{k}$ and $\hat{y}_{k}$ for each sample-time we used the " 8751 Calculator. It is worth mentioning, that the total internal memory EPROM/RAM used in the D8751H was $80 \%$ and $60 \%$, respectively, and that the time spent for the microcontroller to performance the digital filter and the Proportional-Integral controller was of 8 milliseconds (in the worst case) and never exceeds the sample time of the embedded system. In addition for avoid mistakes in the sample time, this time is calculated for an internal timer of the microcontroller, which it active an overflow flag every time that 10 milliseconds has elapsed.

\section{EXPERIMENTAL RESULTS.}

The performance of embedded system was proved with experimental results. Step changes were given like reference signal, particularly small changes in the angular position of the motor. An application of this configuration is in micropositioning; for example, (i) for the control of closing or opening of a valve to handle flow-rates in tubes and (ii) delivery of insulin bolus in the therapy of diabetes mellitus [13]. Figure 6(a) shows the closed-loop response of the plant for three equal changes in the reference signal, each of $78 \mathrm{mV}=0.960$ radians. The magnitude of the steady state errors is $3.8 \%$. Such an error represents 0.036 radians, in angular portion, which fulfills the requirements of imposed performance.

Figure 6(b) shows the voltage calculated by the Pl-controller eq.(9) for each change in the reference signal $(0.960$ radians). Here $U(t)$ is the voltage supplied to the motor in analog form and amplified in current by the power stage (see Figure 1). The maximum current required by the motor in this application is $300 \mathrm{~mA}$. In Figure 6(b), one can notice that there exist noisy measurements in $U(t)$. However, the noise is a high frequency signal and does not affect the angular position of the motor (see Figure 6(a)). 

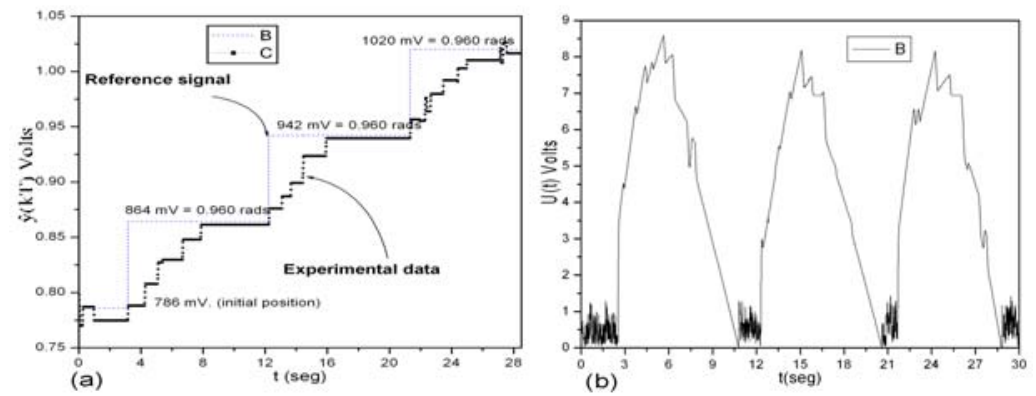

Figure 6. Experimental results showing the performance of the embedded system:

a) Closed-loop response of the plant for a reference signal of $78 \mathrm{mV}=0.960$ radians.

b) Control voltage calculated by the PI-controller and supplied to the motor for each change in the reference signal

\section{CONCLUSIONS.}

In this contribution, we showed that it is possible to implement in the microcontroller $\mathrm{D} 8751 \mathrm{H}$ a discrete-control scheme (in the feedback-configuration) to control a small DC-Gearmotor without using external memory RAM/EPROM. Such microcontrollers are the classical version of INTEL ${ }^{\circledR}$ microcontrollers and were designed specially for intermediate complexity applications and oriented to state control. However, we show that control algorithms (discrete-time filter, PI-controller) and special libraries can be programmed using only its RAM/EPROM internal memory. Besides with the aid of the " 8751 Calculator" the D8751H microcontroller can perform arithmetical operations with 16 and 32 bits.

\section{Acknowledgements}

We thank Professor H.C. Rosu from the Applied Mathematics Division of IPICYT, for his generous comments on this article.

\section{REFERENCES}

[1] Wharton J., Using the INTEL ${ }^{\circ}$ MCS ${ }^{\circ} 51$ Boolean Processing Capabilities, Application Note, AP-70, Intel Corporation, USA, 1980, April. (mww.intel.com)

[2] Katausky J., Horder I., Smith L., Analog/Digital Processing with microcontrollers, Applications Engineers, AR526, Intel Corporation, (mww.intel.com).

[3] López R., Galindo S., Gaytán E., Juárez R., Temperature and Humidity Laboratory Remote Controller, Instrumentation and Development, Vol. 3, Nr. 6, 1996, pp. 14-20

[4] Modares J., Small DC Motor Control, Application Note AP-425, Intel Corporation, USA, 1988, September. (mww.intel.com)

[5] Perez S. J., Calva M.A., Castañeda R., A Microcontroller-Based Data Logging System, Instrumentation and Development, Vol. 3, Nr. 8, 1997, pp-24-30

[6] Franklin G. F., Powell J. D., Digital Control of Dynamic Systems, 2d Ed., Addison-Wesley, 1990

[7] Dorf R. C., Bishop R. H., Modern Control Systems, 7d Ed. Addison-Wesley, 1995

[8] Data Sheet: DAC0800/DAC0802 8-Bit Digital-to-Analog Converters, National Semiconductors Corporation, 1999, June

[9] Data Sheet: ADC1241CIJ Self-Calibrating 12-Bit Plus Sign P-Compatible A/D Converter with Sample-and-Hold, National Semiconductor Corporation, 1994, November

[10] Ogata K., Ingeniería de Control Moderna, 3d Ed., Prentice-Hall, 1998

[11] Franklin G. F., Powell J. D., Feedback Control of Dynamic Systems, 4d Ed., Prentice-Hall, 2002

[12] Data Sheet: DC Permanent Magnet Planetary Gearmotors series CMM \& CLL, E-2030 Pages 10-13. http://www.globe-motors.com/cmmgr_in.pdf

[13] Hernández-Rosales C., Instrumentación de una bomba electromecánica para el suministro de insulina, Tesis de Licenciatura, FC-UASLP, San Luis Potosí, México, 2002 